\title{
ENSAIO FOTOGRÁFICO Os Avá Guarani/Ñandeva de Porto Lindo (Jakarey) Yvy Katu: terra, território e palavras guardadas.
}

\author{
Yan Leite Chaparro ${ }^{1}$ \\ Universidade Federal da Grande Dourados
}

Resumo: O ensaio fotográfico que segue descreve sobre alguns caminhos tecidos durante a pesquisa de campo do trabalho de doutorado intitulado "Este é nosso corpo, a terra: caminhos e palavras Avá Guarani/Ñandeva de Porto Lindo (Jakarey) Yvy Katu para além do fim do mundo”. Imagens que buscam explicitar as palavras guardadas ouvidas durante o decorrer da pesquisa, palavras que caminham e produzem uma complexa realidade nunca desvinculada da terra e do território. Pois, as palavras guardadas Avá Guarani/Ñandeva dizem que são nascidos da terra e que o corpo é a terra.

Palavras-chave: Avá Guarani/Ñandeva; Porto Lindo (Jakarey) Yvy Katu; ensaio fotográfico.

\footnotetext{
${ }^{1}$ Filho de mãe nordestina e pai paraguaio, nascido e criando em um lugar que beira o fascismo e ainda exibe as imagens do faroeste. Daqueles que lutam e ainda acreditam em mundos para além do fim do mundo. Trabalha como pesquisador no campo dos Estudos Críticos do Desenvolvimento, do Antropoceno e da Etnologia Indígena. Trabalha como psicodramatista clínico entre os espaços que permeiam o terapêutico e o social. Graduado em Psicologia pela Universidade Católica Dom Bosco (UCDB), com mestrado e doutorado em Desenvolvimento Local pela Universidade Católica Dom Bosco (UCDB), formado em Psicodrama pelo Instituto Gaya, e pós-doutorando em Antropologia pela Universidade Federal da Grande Dourados (UFGD). Integrante do Grupo de Pesquisa Estudos Críticos do Desenvolvimento/CNPq, do Laboratório de Humanidades (LabuH) e do Grupo de Estudos O Cuidado com os Mundos: sobre o Antropoceno.
} 


\title{
Avakuéra Guarani/Ñandéva Jakarey (Porto Lindo) Yvy Katugua: Yvy, tekoha guasu ha ñe'ẽnguéra ñeñongatupy
}

Ñe'ẽmbyky'i: Ko ta'angaguenohẽ ñeha'ã ohechauka tapekuéra ojejapo hague pe mba'e jeporeka rupi tembiapo doutorado pegua ha'éva "“'Péa ha'e ore rete, yvy tapekuéra ha ñe'ẽnguéra Ava Guarani/Ñandéva Jakareypegua (Porto Lindo) Yvy Katu amogotyove opa'ỹmboyve ko jaikoha”. Ta'angakuéra omombe'uséva ñe'ẽnguéra oñeñongatúva oñehendúva tembiapo jeporeko rupi, ñe'ẽ oguatáva ha ohechaukáva heta mba'e ha katu araka'eve ndojeíri ojohegui yvy ha tekoha guasu. Umi ñe'ẽ ñeñongatupy Ava Guarani he’i yvy membyha ypéagui ko rete ha'e yvy. ko yvy ha'e ore rete

Ñe'ẽte-mbyky'i: Ava Guarani/Ñandéva; Jakarey (Porto Lindo) Yvy Katy; Ta’angaguenohẽ ñeha'ã.

\section{The Avá Guarani/Ñandeva of Porto Lindo (Jakarey) Yvy Katu: earth, territory and kept words}

\begin{abstract}
The photography essay that fallows describes paths weaved during the doctorate field research titled "This is our body the earth: paths and words Avá Guarani/Ñandeva of Porto Lindo (Jakarey) Yvy Katu for beyond the end of the world". Pictures that seek to make explicit the kept words heard throughout the research, words that pass and produce a complex reality never unlinked from the earth and territory. The kept words Avá Guarani/Ñandeva are said to be born of the earth and that the body is the earth.
\end{abstract}

Keywords: Avá Guarani/Ñandeva; Porto Lindo (Jakarey) Yvy Katu; photography essay. 
$\mathrm{O}$

ensaio fotográfico que segue descreve sobre alguns caminhos tecidos durante a pesquisa de campo do trabalho de doutorado intitulado "Este é nosso corpo, a terra: caminhos e palavras Avá Guarani/Ñandeva de Porto Lindo (Jakarey) Yvy Katu para além do fim do mundo". Trabalho que têm como objetivo principal pensar com os Avá Guarani/Ñandeva sobre as questões do desenvolvimento, primeiro: como os Avá Guarani/Ñandeva pensam e produzem sua noção própria de desenvolvimento, e segundo: como os Avá Guarani/Ñandeva historicamente produziram formas de enfrentamentos em relação a imagem da invenção branca de desenvolvimento.

Por isso, as imagens que seguem buscam explicitar as palavras guardadas ouvidas durante o decorrer da pesquisa. Palavras que caminham e produz uma complexa realidade nunca desvinculada da terra e do território. Pois, as palavras guardadas Avá Guarani/Ñandeva dizem que são nascidos da terra e que o corpo é a terra. Imagens escolhidas na busca de levar para quem vê, um caminho, um caminhar pelo território Avá Guarani/Ñandeva Porto Lindo (Jakarey) Yvy Katu situado na fronteira do Brasil com o Paraguai no Mato Grosso do Sul.

Caminho guiado por imagens que por si só, são éticas e políticas, pois revelam um pedaço da realidade de uma sociedade que está em simetria com a sociedade moderna/capitalista, pois ambas são sociedades, mas que caminha por um caminho contrário, e que todos os dias encontra a violência por todos os lados, pelo simples fato de caminhar por outras dimensões como vida e que, ultimamente, aparece como umas das poucas saídas para além do já anunciado fim do mundo.

Recebido em 17 de julho de 2019. Aceito em 22 de julho de 2020. 


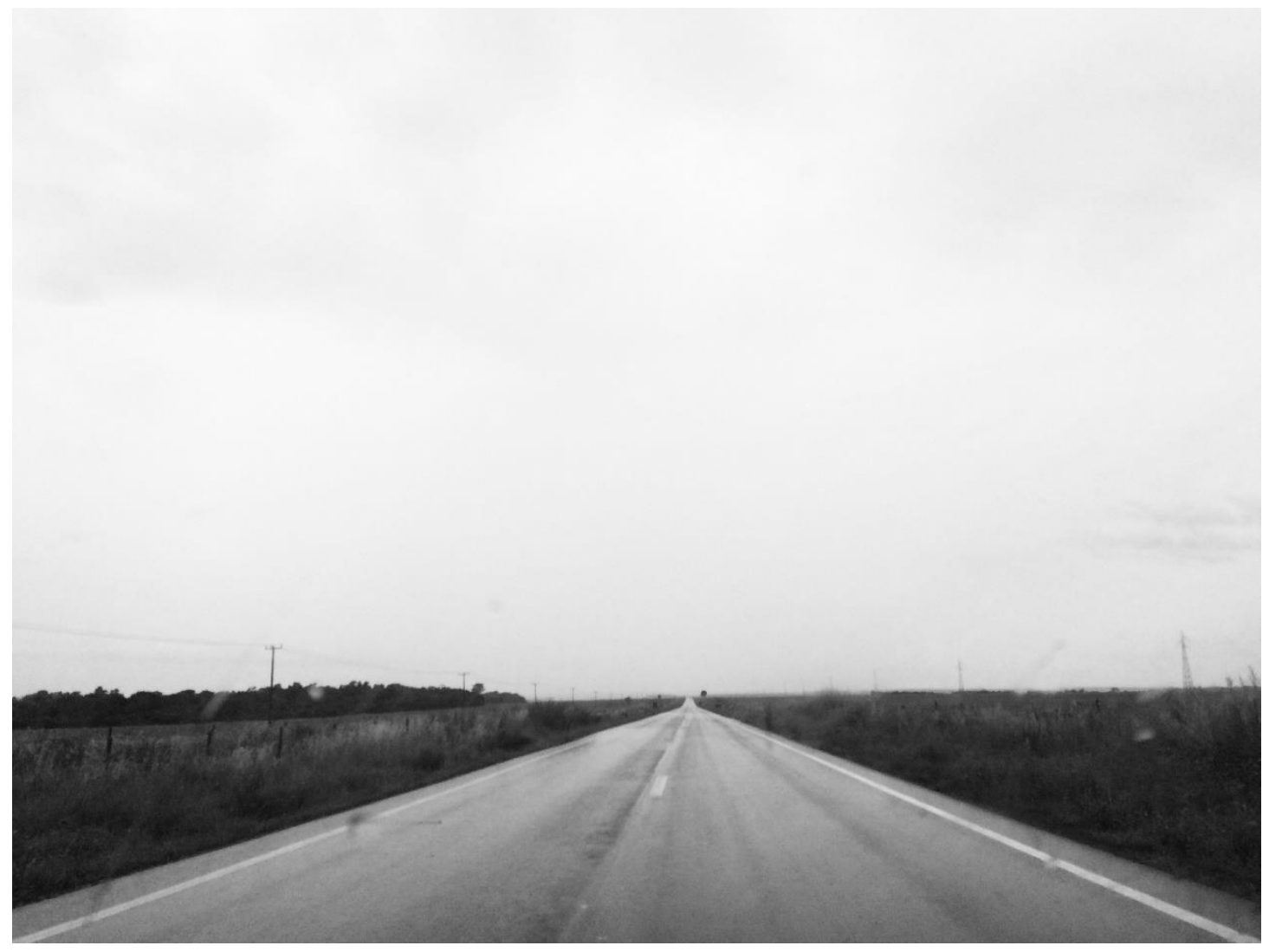

Foto 1 - Empreitada

Rodovia que atravessa a cidade de Amambai/MS, mesma rodovia que corta como projeto de desenvolvimento e progresso os territórios Kaiowá que lá existem, herança do tempo do SPI (Serviço de Proteção aos Índios). Pedaço de asfalto onde é possível ver todos os dias indígenas Kaiowá atravessando e caminhando, revelando todos os dias perigos que chegam de vários lados. Um dos caminhos para chegar no território Guarani Nandeva Porto Lindo (Jakarey) Yvy Katu, que fica no extremo sul do Mato Grosso do Sul, na borda do rio Iguatemi, entre as cidade Iguatemi (MS) e Japorã (MS). 


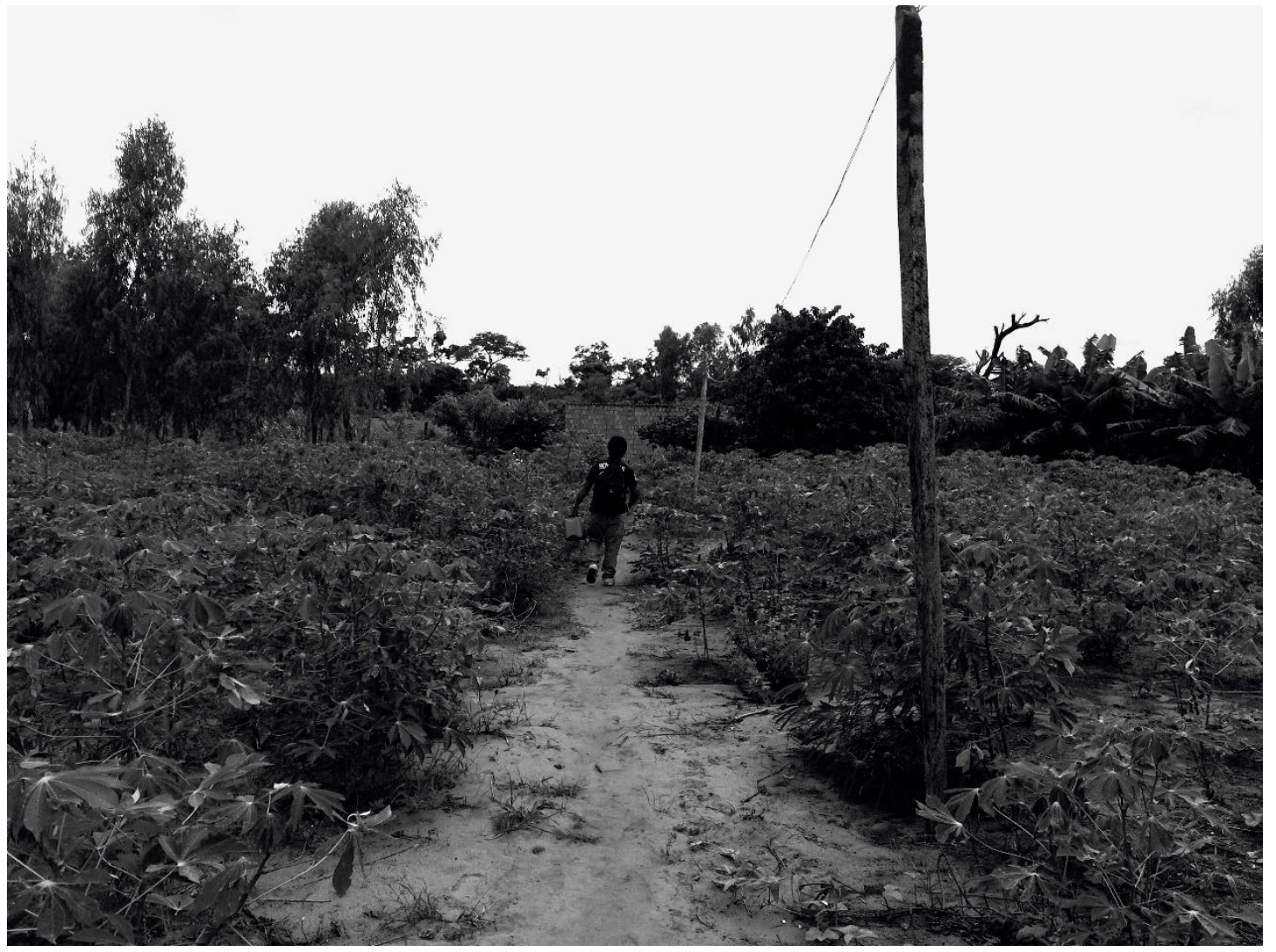

Foto 2 - O caminho entre roças

Entre roças de mandioca, amendoim, milho e plantas medicinais do rezador Cantalicio Godoi no território Porto Lindo (Jakarey) Yvy Katu. Na frente, o professor e pesquisador Guarani Ñandeva Eliezer Martins Rodrigues, parceiro, amigo e companheiro de trabalho e amizade. Eliezer sempre a frente, enquanto o seguia pelos caminhos visíveis e invisíveis. Imagem que explicita todo o processo de campo da pesquisa, muito mais que um guia ou interlocutor, durante a pesquisa foi formado uma aliança de trabalho e amizade, quando no momento que pesquisava para o doutorado em desenvolvimento local, Eliezer pesquisava para seu mestrado em educação. Entre roças, pois é entre roças, picadas, estradas, casas e pátios que é possível olhar com o outro sobre a realidade que se revela. 


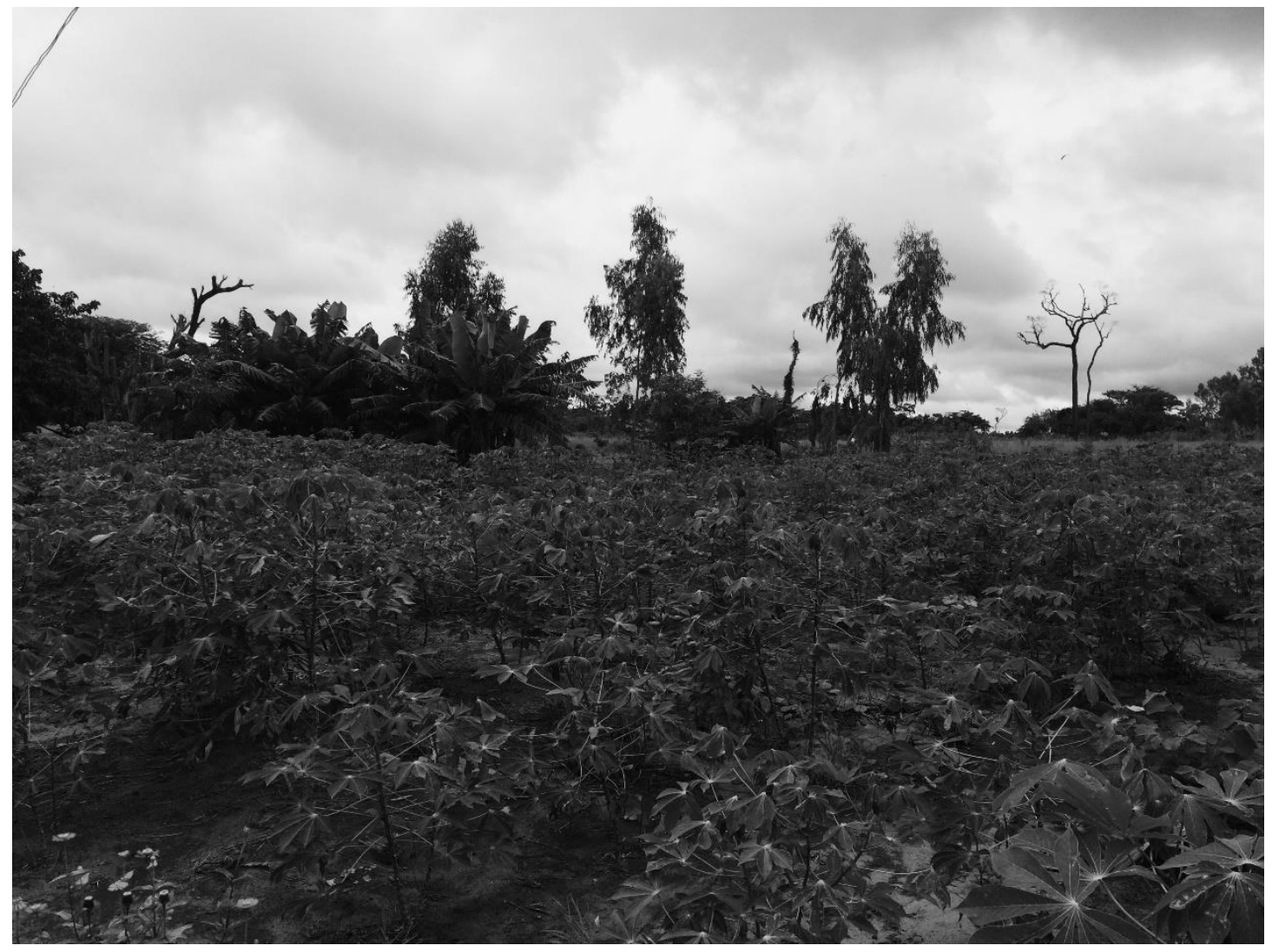

Foto 3 - Roça

Roça tradicional Guarani Nandeva, como disse o rezador Cantalicio Godoi Este é nosso corpo a terra. Ao lado de cada casa Guarani Nandeva existe a roça, e no contorno ainda é possível ver a mata alta como dizem por aqui, mas para os mais atentos essa mata se chama Mata Atlântica. Mata que antes da intervenção de desenvolvimento da Cia Matte Laranjeira, também guardava árvores e mais árvores de Erva Mate. O corpo é a terra, e a terra é o corpo, a roça é produzida pelos seres não-humanos, alimentos e Jara `s (donos) que ajudam a conduzir e organizar o espaço cosmopolítico da roça. Microcosmo que guarda nas palavras dos sábios Guarani Ñandeva caminhos para além do fim do mundo. 


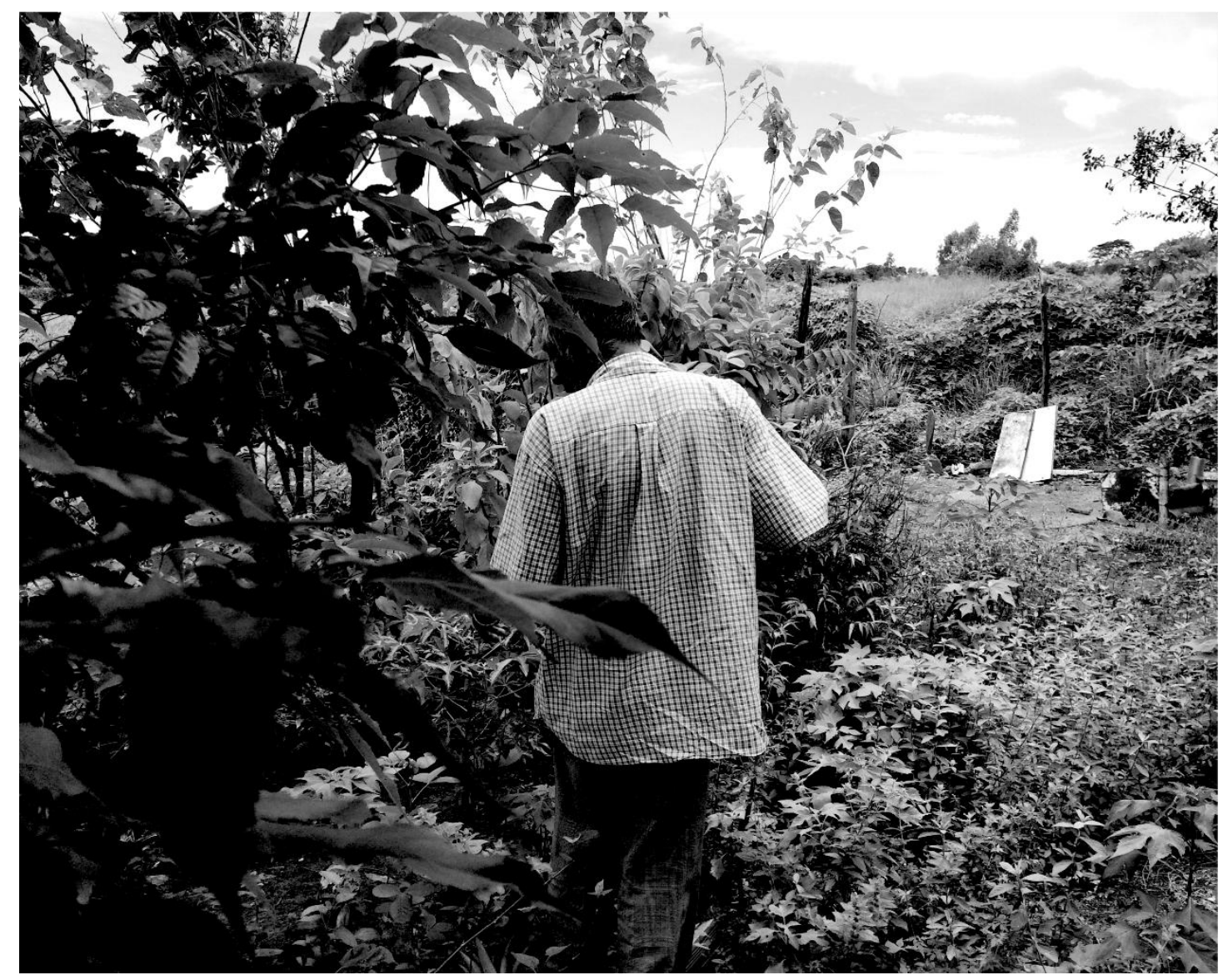

Foto 4 - Remédios

Roça de remédios do sábio Guarani Nandeva Sabino Dias (in memoriam). Ao lado de sua casa, contornada pela roça tradicional de milho e mandioca, Sabino Dias cuidava de uma roça somente de plantas medicinais, pois ali chegavam pessoas de vários lugares para buscar remédios tradicionais, pois os lugares brancos dos hospitais e outros espaços de saúde causa ainda muito estranhamento. Ao fundo da casa de seu Sabino, ele cuidava de uma nascente de água, cuida junto com alguns Jara `s, que ali se revelam como uma Sucuri e alguns peixes. A casa de Sabino Dias fica na retomada Yvy Katu, e a nascente que ele cuidava antes era uma água para gado beber, estava suja e poluída de coisas de gado e veneno. A retomada de Yvy Katu aconteceu há poucos anos, e por isso hoje chamamos de Porto Lindo (o nome da antiga reserva) Jakarey (o nome tradicional onde ficava a antiga reserva) Yvy Katu (a retomada Guarani Ñandeva, que hoje abriga várias aldeias Guarani Ñandeva), retomada que hoje sofre perigos por conta de projetos como o Marco Temporal. 


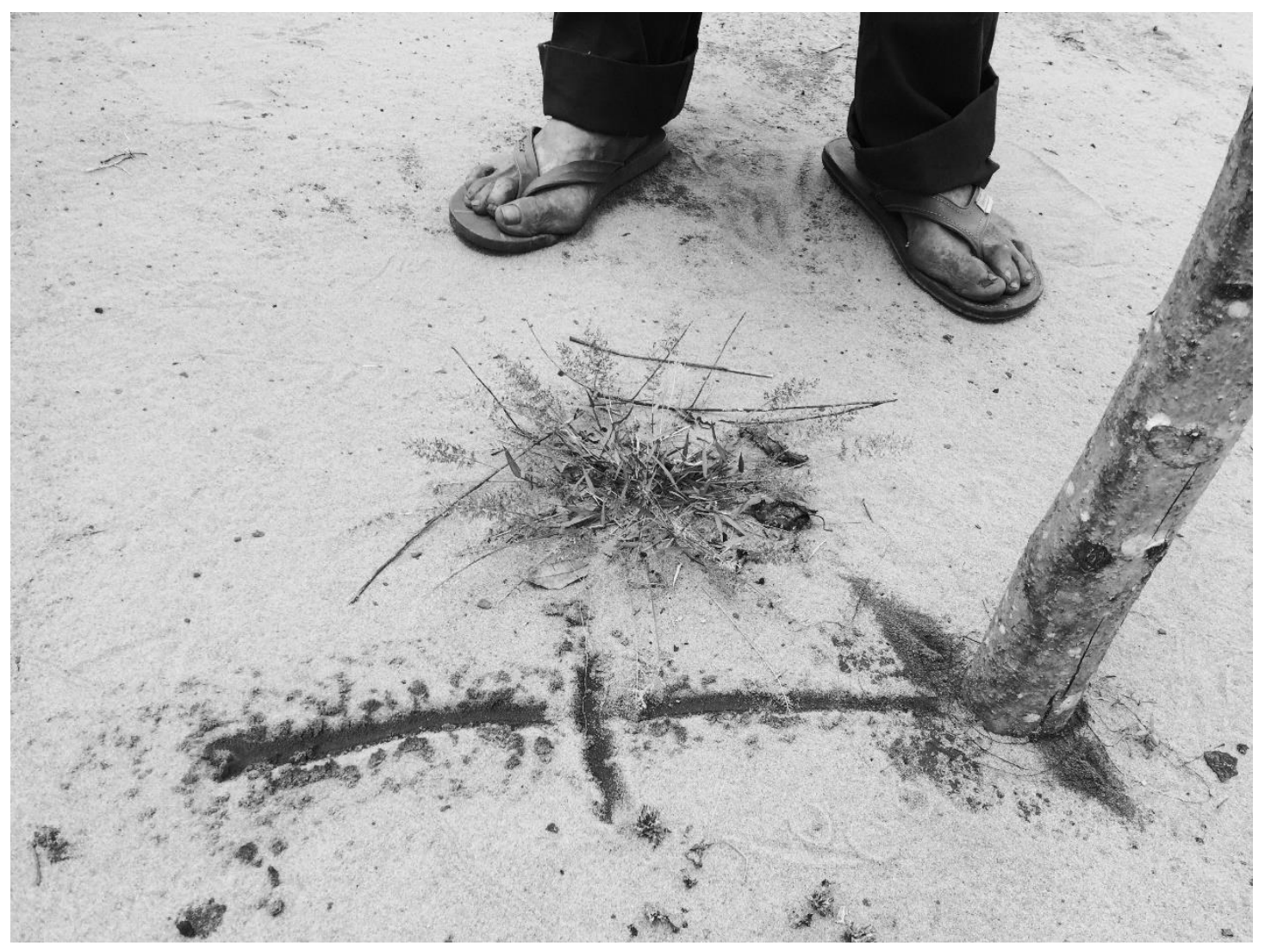

Foto 5 - Quanto dói o peito?

O risco no chão e os pés são do rezador Cantalicio Godoi, riscos que saem do pé de uma árvore de Cedro, árvore que possui bastante importância para o cotidiano dos Guarani Ñandeva, está no remédio, está nos objetos/pessoas de reza, está como água no batismo das crianças, e está na vela quando uma pessoa falece. A imagem produzida por Cantalicio Godoi diz sobre um remédio para doenças do coração, a marca no chão diz o lugar e o jeito exato para colher a raiz do Cedro para fazer o remédio. Pés, terra, planta, remédios e conhecimentos, um microcosmo que diz um pouco sobre o Yvy Pora (a noção de pessoa) Guarani Ñandeva, uma noção que dobra e desdobra a relação natureza e cultura, e que coloca a pessoa como guardião e pertencente a terra, e não como ente moderno que não aterra. 


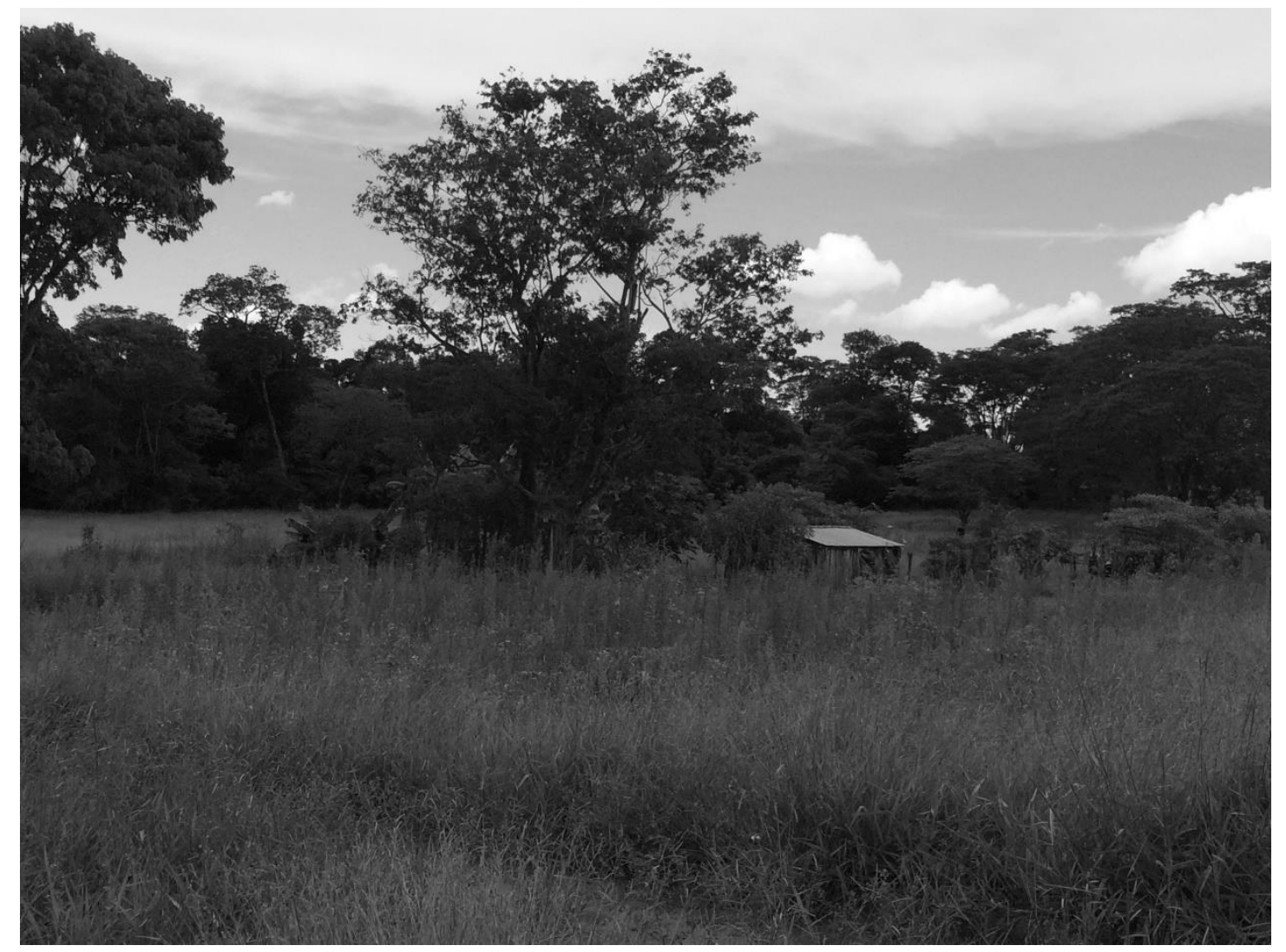

Foto 6 - Casa

Casa de uma família Guarani Ñandeva contornada pela roça tradicional, árvores frutíferas e por uma mata alta, ou melhor, pela Mata Atlântica. Casa que fica na retomada de Yvy Katu, hoje Porto Lindo (Jakarey) Yvy Katu, mas que alguns anos atrás era uma fazenda. Retomada que recupera o território Guarani Ñandeva, ao mesmo tempo que retoma o Ñande Reko Guarani Ñandeva, que por conta do processo de histórico de expulsão dos seus territórios, ficava um pouco em silêncio, mas como um amigo Guarani Nandeva diz, retomar nosso território é também retomar nosso modo de vida Guarani Ñandeva, que hoje não precisa mais ficar em silêncio. 


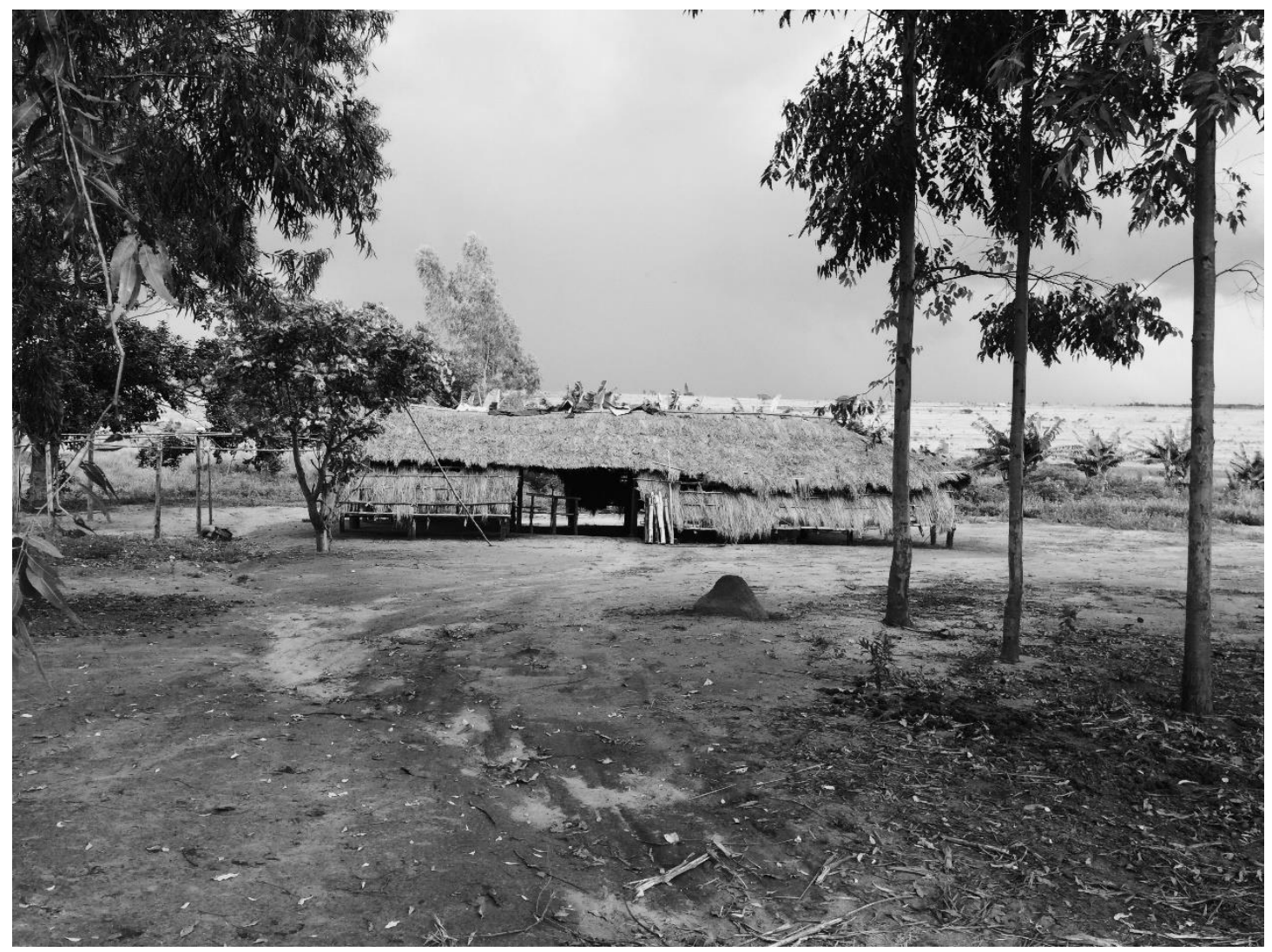

Foto 7 - Casa de reza

Casa de reza pertencente ao sábio Rosalino Ortiz, casa que é espaço de cerimonias como o batismo e outros, mas também é um espaço de ensino para os mais novos, e políticos, para longas conversas sobre a realidade de Porto Lindo (Jakarey) Yvy Katu. Igual a roça, essa casa não está imóvel, mas transita pelo cotidiano dos Guarani Nandeva, como várias redes, esses lugares pertencem ao cotidiano, ao Nande Reko (modo de vida) Guarani Ñandeva. Um cotidiano permeado por humanos e não-humanos que produz uma organização cosmopolítica e de alteridades com muitos outros, esses pertencentes ao Nande Reko Guarani Ñandeva e ao Ñande Karai (modo de vida dos brancos). Por isso, muitos passam e não enxergam o que só é possível de enxergar quando o caminho é produzido com os Guarani Nandeva. 


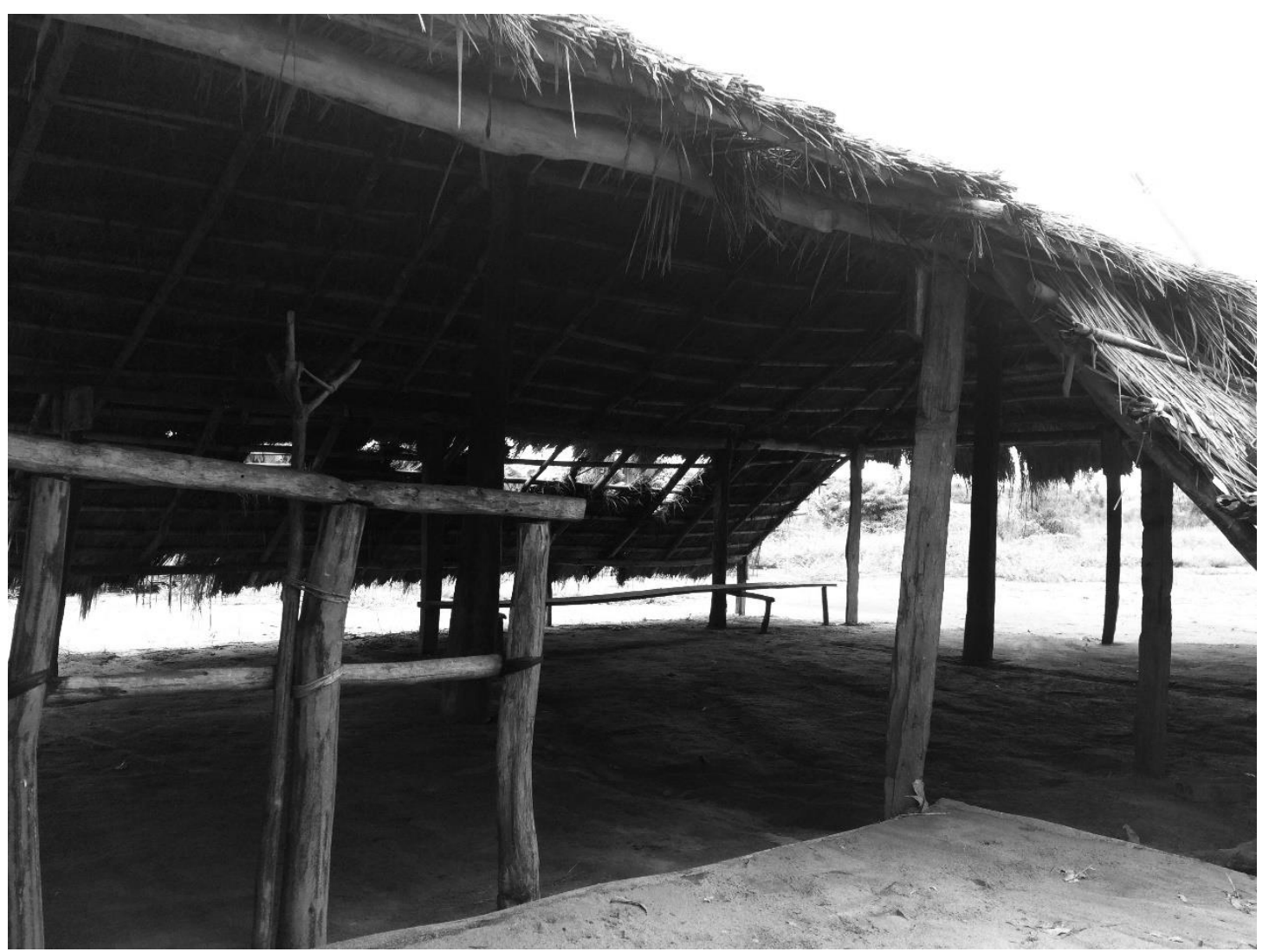

Foto 8 - Tataendy

Tataendy feito do Cedro, que fica em uma parte central da casa de reza, espaço onde os rezadores e as rezadoras pronunciam suas rezas e seus cantos de cura e cuidado para o mundo Guarani Nandeva, e para os outros mundos, pois como disse o rezador Cantalicio Godoi, são os Guarani Nandeva que possuem as coisas dos Deuses, e são eles com suas coisas que podem devolver algum novo equilíbrio para o mundo (o planeta terra) que já está todo comido por cupim. 


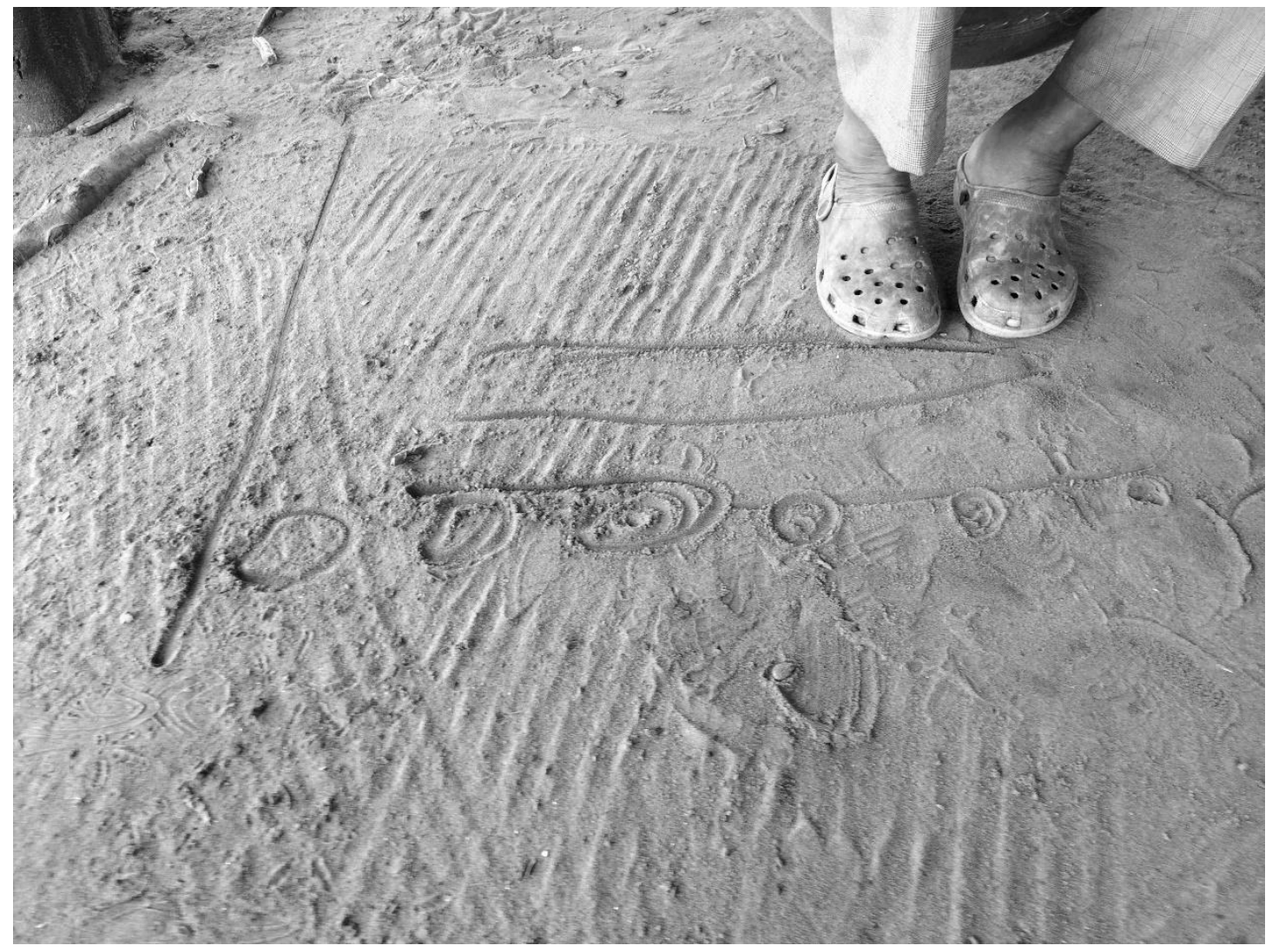

Foto 9 - O grande território Guarani Ñandeva

Desenho riscado na terra pelo sábio Sabino Dias, e que revela a imagem histórica dos Guarani Ñandeva que vivem a beira do rio Iguatemi, cada circulo representa uma aldeia antiga na beira do rio Iguatemi até o rio Paraná que fica na fronteira entre os Estados do Mato Grosso do Sul e do Paraná. Desenho que explicita a expulsão dos Guarani Ñandeva dos seus territórios, esses sequestrados principalmente na época da Cia Matte Laranjeira. Territórios que estão na memória dos mais velhos, nos escritos de Curt Nimuendaju, Pierre Clastres e Egon Schaden, e hoje na memória presente dos mais novos. Imagem que também explicita os projetos de desenvolvimento instituídos e atrelados no processo de expulsão dos Guarani Ñandeva dos seus territórios, projetos esses que já teve a face da Guerra da Tríplice Aliança, da Cia Matte Laranjeira, do SPI, da Colônia Agrícola Nacional de Dourados, e hoje se apresenta com o avanço cada vez maior da indústria do agronegócio. 